\title{
Effectiveness of Erythropoietin in Hypertensive Hemodialysis Patients
}

\author{
Susannia Ibrahim ${ }^{1}$, Ajeng Diantini ${ }^{2}$, Budhi Prihartanto ${ }^{2}$, Rudi Supriyadi ${ }^{3}$ \\ ${ }^{1}$ Regional Public Hospital of Sumedang, Sumedang, West Java, Indonesia \\ ${ }^{2}$ Department of Pharmacology and Clinical Pharmacy, Faculty of Pharmacy, \\ Universitas Padjadjaran, Jatinangor, West Java, Indonesia \\ ${ }^{3}$ Department of Internal Medicine, Faculty of Medicine, \\ Universitas Padjadjaran, Jatinangor, West Java, Indonesia
}

\begin{abstract}
Chronic renal failure (CRF) is one the most prevalent health problems among the elderly. On the fifth stage of CRF, the patient becomes eligible to hemodialysis. CRF-induced anemia is commonly treated with Erythropoietin (Epo). Information regarding the effectiveness of Epo in hypertensive hemodialysis patients was limited. Therefore, this study was conducted to evaluate the effectiveness of Epo in hypertensive hemodialysis patients. This study used an observational case-control analytic method. Data were retrieved from the medical records of hemodialysis patients during March-May 2014. A total of 54 participants were included. The increase of haemoglobin $(\mathrm{Hb})$ in controlled hypertension was $0.6257 \mathrm{~g} / \mathrm{dl}$, while the in uncontrolled hypertension group, there was a decrease in $\mathrm{Hb}(-0.1590 \mathrm{~g} / \mathrm{dl})$. The use of Epo was more effective in hemodialysis patients with controlled hypertension.
\end{abstract}

Keywords: chronic kidney disease, erythropoietin, hypertension

\section{Introduction}

Chronic renal failure (CRF) is one the most prevalence health problems among the the elderly. On the fifth stage of CRF, the patient becomes eligible to start hemodialysis to remove accumulated toxins from the body. ${ }^{1}$ In Indonesia, the number of patients with renal failure was approximately 150,000 patients and the number of hemodialysis patients reached $22600^{2,3}$
The costs incurred for CRF therapy are enormous. According to United States renal data system report in 2012, the total cost for chronic kidney failure patients was 3.35 billion dollars, of which $13 \%$ was accounted for stage 4-5 of CRF. ${ }^{4}$

Kidney is the main source of erythropoietin (EPo), a hematopoietic growth factor that spur the formation of red blood cells. Epo

Corresponding author: Susannia Ibrahim, Regional Public Hospital of Sumedang, Sumedang, West Java, Indonesia. Email : susanniaibrahim2@gmail.com 
increases the production of reticulocytes and premature reticulocytes from the bone marrow. In CRF patients, Epo production is inadequate, thus anemia often occurs. ${ }^{5,6} \mathrm{CRF}$ induced anemia is commonly treated with Epo drug. Several studies have shown that administration of Epo may reduce hospital admissions and improve the quality of life of patients. ${ }^{7,8}$

One of the factors that aggravates CRF in hemodialysis patient is the presence of other complicating medical condition such as uncontrolled hypertension. Several hypertensive guidelines highlight the importance of lowering blood pressure (BP) to slow the progression of CRF.

Information regarding the effectiveness of Epo in hypertensive hemodialysis patients was limited. Therefore, this study was conducted to evaluate the effectiveness of Epo in hypertensive hemodialysis patients.

\section{Methods}

This research was a retrospective observational case control study conducted during March-May 2014 in a hospital in Sumedang, Indonesia. The data were collected from medical records.

The inclusion criteria were subjects with CRF who underwent hemodialysis, received Epo therapy (2000 IU), and had hypertension. Exclusion criteria were patients who received blood transfusion, had bleeding and infection, and had incomplete medical records.

From each subject, the following data were extracted: general characteristics, hemoglobin

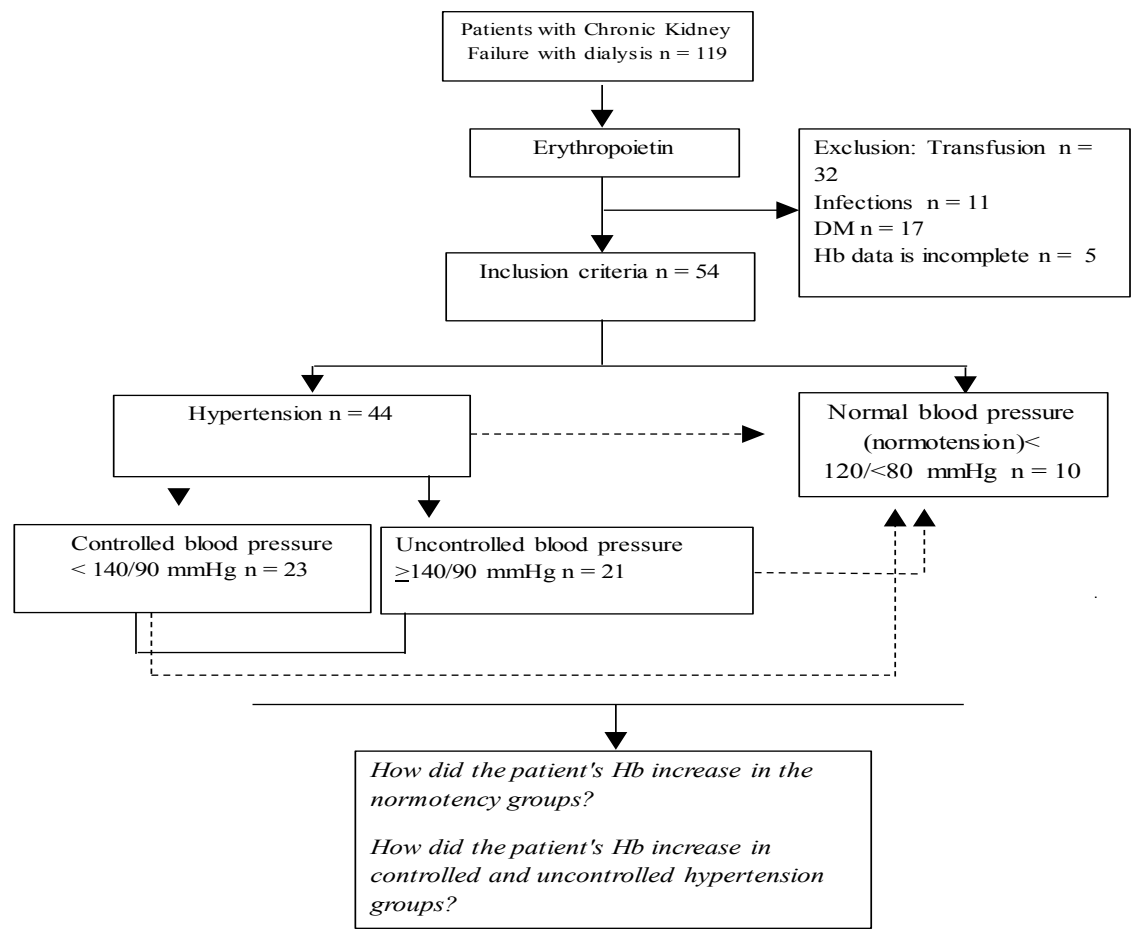

Figure 1. Diagram of subjects selection 


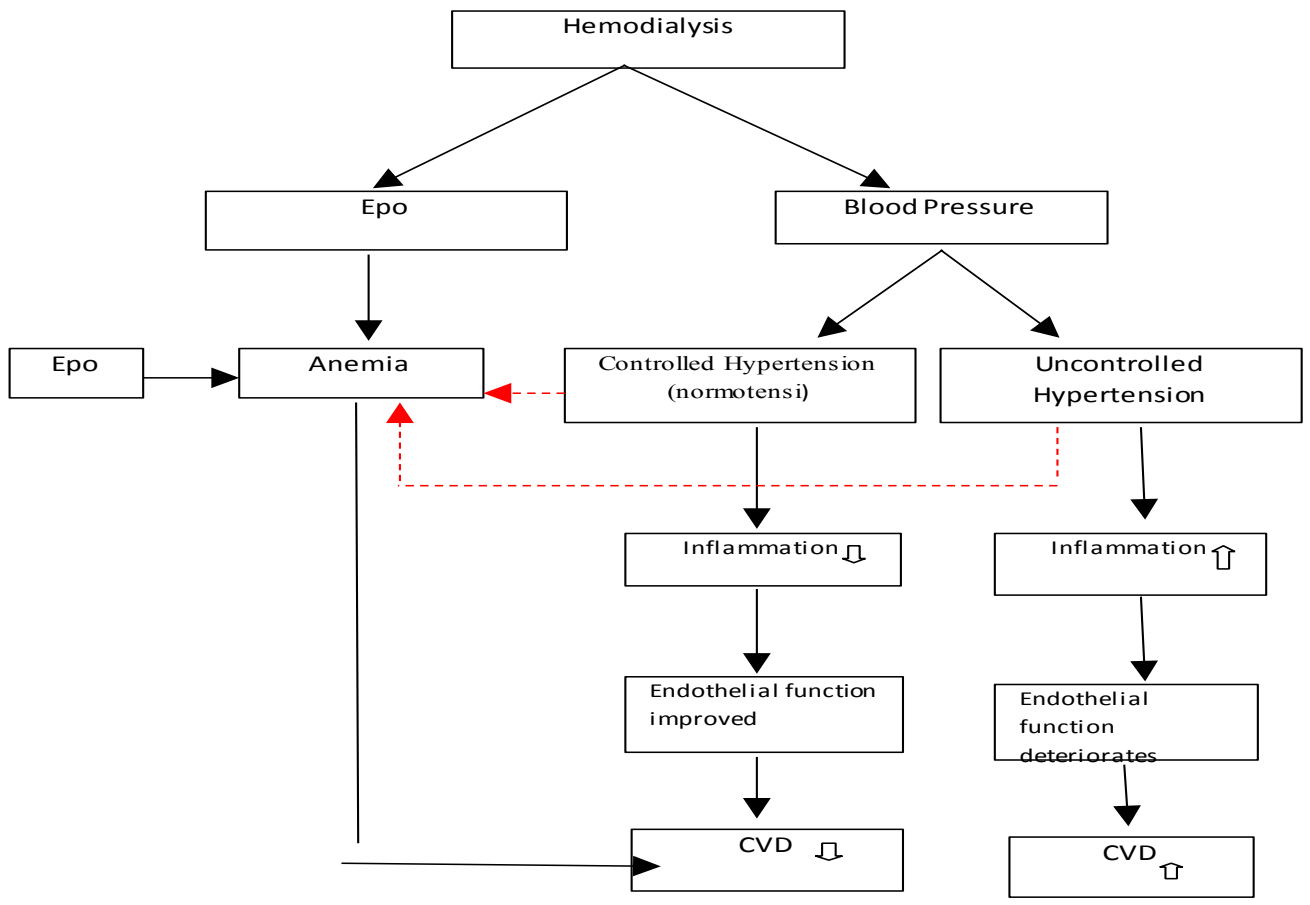

Figure 3. Research framework

$(\mathrm{Hb})$ during study period, duration and frequency of Epo treatment, and BP. Epo was given once a week with the dose of 2.000 IU. Data were analyzed using Cruciate test of Wallis. Significance was set at $\mathrm{P}<0.05$.

\section{Results and Discussion}

The total population of outpatient hemodialysis was 119 patients. However 65 subjects were excluded due to nontraceable medical records (5), received blood transfusion (32), received antibiotics due to infection (11), and patients with complicated diseases other than hypertension (17). A total of 54 subjects were included. The subjects were classifed into 3 groups, namely controlled hypertension group (BP $\leq 140 / 90$ $\mathrm{mmHg}$ ), uncontrolled hypertension group
$(\mathrm{BP}>140 / 90 \mathrm{mmHg}$ ) and normal group as standard $(\mathrm{BP} \leq 120 / 80 \mathrm{mmHg})^{7}$

More than half of the subjects were male $(59.09 \%)$, aged 51-60 years old $(45.45 \%)$. Increased risk of CRF was observed for those who aged $>55$ (male) and $>65$ (female) due to decreased organ functions and regulating hormones. ${ }^{89}$ More than two-thirds of patients used combinations of antihypertensive drugs. Angiotensin converting enzyme inhibitors (ACEI) or angiotensin receptor blocker (ARB) is the drug of choice for hypertension therapy in renal vascular disorder. ${ }^{10}$

The mean increase of $\mathrm{Hb}$ in normal BP group, and controlled hypertension group were 0.62 $\mathrm{g} / \mathrm{dl}$ and $0.49 \mathrm{~g} / \mathrm{dl}$. However, in unctrolled BP 
group, there was a decrease in $\mathrm{Hb}(-0.15 \mathrm{~g} /$ dl).

Uncontrolled BP potentially aggravates kidney damage. Continuously developing high BP will increase the glomerular pressure into tenuous, causing endothelial dysfunction, following by necrosis and inflammation of the renal filter layer components, resulting in fibrosis and finally, a decrease in GFR..$^{11,12}$

The more severe of the kidney damage, the higher risk of anemia in hemodialysis patient. Thus, it is necessary to control BP on hemodialysis patients to reduce disease burden. ${ }^{13}$

\section{Conclusion}

The use of Epo was more effective in hemodialysis patients with controlled hypertension patients compared to uncontrolled hypertension.

\section{Acknowledgement}

None.

\section{Funding}

None.

\section{Conflict of Interest}

None declared

\section{References}

1. Abraham G, Varughese $S$, Thandavan $T$, et al. Chronic kidney disease hotspots in developing countries in South Asia. Clinical Kidney Journal. 2016;9(1):135141.

2. United Stated Renal Data System (USRDS). Annual Data Report: Costs of Chronic Kidney Disease, vol 1;2012.

3. Bamgbola OF. Pattern of resistance to erythropoietin-stimulating agents in chronic kidney disease. Kidney International. 2011;80:464-474.
4. Gombotz H. Patient blood management: a patient-oriented approach to blood replacement with the goal of reducing anemia, blood loss and the need for blood transfusion in elective surgery. Transfusion Medicine and Hemotherapy. 2012;39:67-72.

5. Barri YM. Hypertension and kidney disease: a deadly connection. Current Hypertension Reports. 2008;10(1):39-45.

6. Thomas R, Kanso A, Sedor JR. Chronic kidney disease and its complications. Primary Care. 2008;35(2):329-44.

7. Stern A, Sachdeva S, Kapoor R, Singh $\mathrm{J}$, Sachdeva S. High blood pressure in dialysis patients: cause, pathophysiology, influence on morbidity, mortality and management. Journal of Clinical and Diagnostic Research. 2014;8(6):ME01ME04.

8. Provatopoulou ST, Ziroyiannis PN. Clinical use of erythropoietin in chronic kidney disease: outcomes and future prospects. Hippokratia. 2011;15(2):109115.

9. Giles TD, Materson BJ, Cohn JN, and Kostis JB. Definition and classification of hypertension: an update. The Journal of Clinical Hypertension. 2009;11(11):6114.

10. Kazancioğlu R. Risk factors for chronic kidney disease: an update. Kidney International Supplements. 2013;3(4):368-371.

11. Mallappallil M, Friedman EA, Delano BG, McFarlane SI, Salifu MO. Chronic kidney disease in the elderly: evaluation and management. Clinical Practice. 2014;11(5):525-535.

12. Becker DE. Adverse Drug interactions. Anesthesia Progress. 2011;58(1):31-41.

13. Nguyen Q, Dominguez J, Nguyen L, Gullapalli N. Hypertension management: An update. American Health \& Drug Benefits. 2010;3(1):47-56. 